\title{
Benefits and Costs of Campaign-Style \\ Environmental Implementation: Evidence from China's Central Environmental Protection Inspection System
}

Dan Pan ( $\square$ pandan@jxufe.edu.cn )

Jiangxi University of Finance and Economics https://orcid.org/0000-0001-7204-6313

Wei Hong

Jiangxi University of Finance and Economics

\section{Research Article}

Keywords: Campaign-style environmental implementation, Cost-benefit analysis Central Environmental Protection Inspection, Water pollution, Difference-in-differences method

Posted Date: September 8th, 2021

DOl: https://doi.org/10.21203/rs.3.rs-772735/v1

License: (c) (1) This work is licensed under a Creative Commons Attribution 4.0 International License. Read Full License

Version of Record: A version of this preprint was published at Environmental Science and Pollution Research on February 10th, 2022. See the published version at https://doi.org/10.1007/s11356-02218750-w. 


\title{
Title page
}

\section{Benefits and Costs of Campaign-Style Environmental Implementation: Evidence from China's Central Environmental Protection Inspection System}

\author{
Dan Pan*, Wei Hong \\ School of Economics, Jiangxi University of Finance and Economics, Nanchang \\ 330013, China
}

*Corresponding author

Dan Pan

Ph.D., Professor in Jiangxi University of Finance and Economics

Address: School of Economics, Jiangxi University of Finance and Economics, Nanchang, Jiangxi, 330013, China

E-mail: pandan@jxufe.edu.cn

Mobile: 86-18070062881

\section{Acknowledgment}

This study was supported by the National Youth Talent Support Program, and the National Natural Science Foundation of China (No. 71863016; No. 71673123) 
1 Benefits and Costs of Campaign-Style Environmental 2 Implementation: Evidence from China's Central 3 Environmental Protection Inspection System

4 Dan Pan ${ }^{1 *}$, Wei Hong 1

1 School of Economics, Jiangxi University of Finance and Economics, Jiangxi Province 330013, China; e-mail: pandan@jxufe.edu.cn (D. P.); hongggggwei@ 163.com (W. H.)

* Correspondence: pandan@jxufe.edu.cn (D. P.); Tel.: +86-791-8381-6042

Abstract

Campaign-style environmental implementation (CEI) is widely exerted in environmental protection, while its benefits and costs are controversial. We take advantage of the Central Environmental Protection Inspection (CEPI) System - a latest and distinguished form of CEI launched by China in 2016, as a quasi-natural experiment to compare the benefits and costs of CEI based on water pollution effects estimates. Our results based on the annual panel data from 500 cities during 2009-2018 show that CEPI significantly reduced water pollution by an average of $11.2 \%$. Further cost-benefit analysis based on the estimates of water pollution reduction shows that the potential health benefits of mortality and morbidity reduction resulting from CEPI are at least $\$ 279.5$ billion, which is greater than the $\$ 192.2$ billion economic losses it causes. The gap is further magnified after considering the potential biases. We also explore why CEPI is cost-effective and find that CEPI reduces water pollution and becomes cost-effective mainly through deterring local officials, punishing polluting enterprises, and increasing public participation in environmental governance.

Keywords Campaign-style environmental implementation

Cost-benefit analysis Central Environmental Protection Inspection Water pollution

Difference-in-differences method

\section{Introduction}

Campaign-style environmental implementation (CEI), a particular type of policy enforcement incorporating high concentrated mobilization of governmental resources under political sponsorship to realize a specific pollution reduction goal in a limited time (Liu et al., 2015), has emerged as one of the most widespread and long-lasting strategies of environmental protection in China (van der Kamp, 2017). CEI's measures are abrupt and severe, such as forcibly closing down entire polluting industries, arbitrarily demolishing outdated factory equipment, and levying high fines 
to polluting enterprises. Through these measures, CEI may be effective in improving environmental quality, but it is also an extremely costly strategy (Jia and Chen, 2019). Whether it is necessary to conduct such high-cost CEI is still controversial. However, little systematic knowledge is known about CEI's benefits and costs, despite the enormous policy implications. In this study, by estimating CEI's impacts on water pollution, we conduct a calculation to compare the benefits and costs of CEI based on water pollution effects estimates.

More specifically, we take advantage of the Central Environmental Protection Inspection (CEPI) System promulgated by China in 2016 as a quasi-natural experiment and employ a difference-in-differences (DID) method to empirically quantify the potential health benefits and economic costs of CEI. And we also explore the mechanism through which the benefits and costs happen. We find that the potential health benefits of CEPI from reduced mortality and morbidity due to improved water quality are at least $\$ 279.5$ billion, while the economic costs of CEPI to the Chinese economy are only $\$ 192.2$ billion. The actual return from CEPI would be even greater, considering that we have only calculated the health benefits from the partial reduction in disease caused by water pollution and that CEPI has mainly eliminated the outdated production capacity.

CEPI, a latest and distinguished form of CEI launched by China in 2016, provides us a perfect setting for investigating the benefits and costs of CEI. CEPI is a watershed moment in the history of China's environmental inspection (Li et al., 2020). Under CEPI, the central government sends inspection teams led by ministry-level cadres into various provinces to check whether local governments implement environmental protection policies and some prominent environmental issues. It then requires local governments to fulfill their enforcement responsibilities (Xu et al., 2020). Every province will receive a CEPI feedback list after completing the inspection, covering all major environmental problems in the water, air, soil, and other environmental issues. The provincial governments must provide corrective action plans based on the lists to address these major environmental pollution problems. We take advantage of CEPI as a natural experiment to estimate the benefits and costs of CEI.

We make four main contributions to the literature. First, to our knowledge, this paper is the first one to focus on the benefits and costs of CEI in the world's biggest developing country. Existing research has focused chiefly on how CEI affects pollution reduction (He and Geng, 2020; Jia and Chen, 2019; Wu and $\mathrm{Hu}, 2019$ ), firm performance (Tian et al., 2019; Zeng et al., 2021), and social involvement (Li et al., 2020; Xiang and van Gevelt, 2020). The lack of scientific evidence on the health benefits and economic costs of CEI makes its effectiveness controversial and thus hinders the government to better launch CEI. Our empirical results highlight the 
pollution reduction of CEI in the world's biggest developing economy, many of which are suffering the worst health burden from severe pollution (Landrigan et al., 2018). CEI's success in China provides a benchmark for cost-benefit policy discussions on launching CEI in other countries.

Second, we add to an emerging strand of literature estimating the impact of environmental implementation on water pollution. Due to data availability and quality, existing studies mainly focus on the effects of environmental implementation on air pollution, while water pollution has largely been ignored (Gray, 2015). Water pollution has profound adverse impacts not only on human health but also on ecosystem services (Greenstone et al., 2021). While the air quality in China has upgraded in the past decade, the water quality, especially the groundwater quality, has degraded: almost $67 \%$ of groundwater does not meet drinking water standards, 190 million people got sick, and 60,000 people have died from diseases because of contaminated water every year in China (Tao and Xin, 2014). Thus, understanding CEI's effect on water pollution is crucial for the government to control water pollution better.

Third, we test the mechanism underlying the benefits and costs of CEI. Previous studies mostly lack the test of the mechanism of CEI. One exception is Jia and Chen (2019), who propose three mechanisms of CEI - shuffle the local incentive structure, alter the internal bureaucratic dynamics, and ignite public participation. However, they only offer theoretical explanations and exploratory evidence, but not empirical analysis for these three mechanisms. Our paper complements the study of Jia and Chen (2019) by empirically analyzing the mechanisms involved in CEI and thus can help the government find out which type of policy tools could be used to strengthen CEI's performance.

Fourth, our paper also relates to the growing discussion on the political economy of environmental regulation by conducting a cost-benefit analysis and showing CEI's working mechanisms. CEI's effectiveness is always controversial, and many scholars have doubted why the Chinese government chooses CEI - an unsophisticated, costly method, as the primary means for pollution control (Liu et al., 2015; van der Kamp, 2017). Our findings highlight that if health benefits are considered, the advantages of CEI are more pronounced, and thus CEI may be a more reasonable choice for an authoritarian state, such as China. Moreover, as the largest developing country in an authoritarian system, our analysis in China is globally relevant that can provide an intermedium to figure out the effectiveness and working mechanisms of CEI, which is beneficial to other developing or transitioning countries.

The remainder of this paper is structured as follows. Section 2 introduces the policy background of CEPI and its impact on pollution control in China. Section 3 provides an overview of the data and methods needed for this paper. Section 4 reports 
115 the baseline results of the impact of CEPI on water pollution. Section 5 shows the

116 estimation results of the benefits and costs of CEPI based on the water pollution

117 effects estimation in Section 4. Section 6 explores the mechanisms why CEPI is

118 cost-effective. Section 7 presents conclusions and corresponding policy

119 recommendations.

\section{Background}

\section{CEPI in China}

122 One major critical challenge in environmental management in China, as well as many 123 other developing countries, is the deficit in policy implementation (Duflo et al., 2018;

124 Li et al., 2019; Shimshack, 2014). In the Chinese "top-down" environmental 125 regulation structure, the effectiveness of environmental regulations depends mainly on 126 the implementation efforts of local governments (Tian et al., 2019; Sun et al., 2021).

127 However, there is a conflict of interest between the central government - the 128 policymaker, and the local governments - the policy implementers, in environmental 129 governance targets (Liu et al., 2016), which leads to a growing phenomenon of weak 130 implementation and lax regulation by local governments in environmental 131 management (Ran, 2013; Yu and Wang, 2013).

132 Against this background, CEPI, as the latest and distinguished form of CEI, has 133 been officially launched in January 2016 to improve the implementation effectiveness 134 of environmental management ( $\mathrm{Li}$ et al., 2020). Different from previous 135 environmental regulation means that simply supervise enterprises, CEPI focuses on 136 supervising governments to impose pressure on local governments and to force them 137 to fulfill their environmental implementation responsibilities (Ding et al., 2021; Xu et 138 al., 2020). The central government sends CEPI teams, led by ad hoc high-ranking 139 cadres, into different provinces to check whether the local governments implement 140 environmental protection policies and some prominent environmental issues (Xiang 141 and van Gevelt, 2020). As a response, local governments are inclined to comply with 142 environmental regulations by closing down polluting industries, stopping production, 143 demolishing outdated factory equipment, and levying high fines to polluting 144 enterprises, and thus to achieve the environmental target within a short time (Karplus 145 and $\mathrm{Wu}, 2019)$.

146 CEPI consisted of five successive batches, starting in January 2016 and ending in 147 September 2017, and covered all 31 provinces in China. Fig. 1 reports the location 148 distribution of the provinces inspected in each batch. We can find that geographically 149 each batch covers provinces in the Chinese three East-Central-West regions, 150 indicating there is no geographical bias in the sample selection process, and there 151 would be no difference in CEPI implementation. 
152

153

154

155

156

157

158

159

160

161

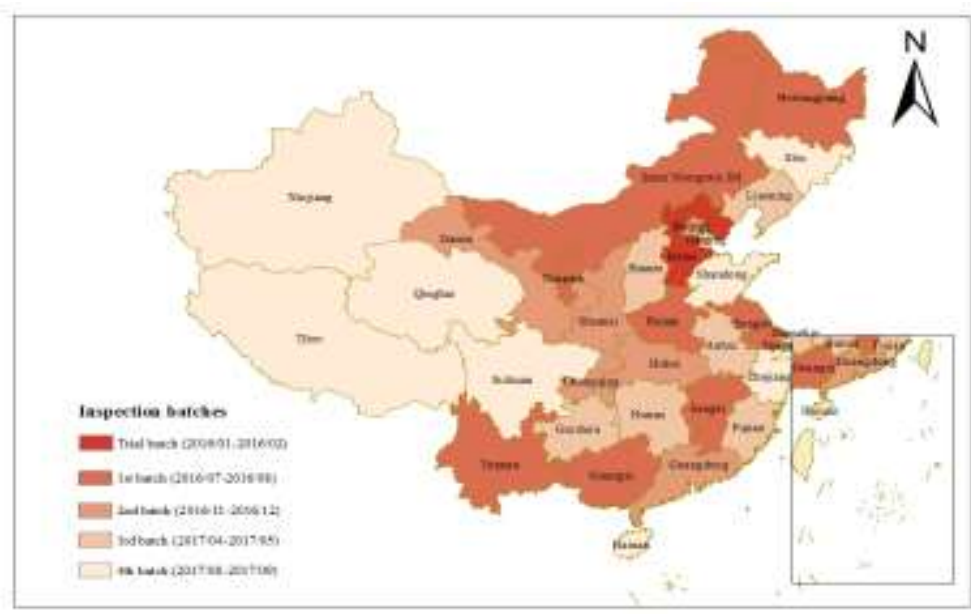

Fig. 1 Geographical distribution map of provinces by CEPI inspection batches

CEPI has resulted in unprecedented investigations and punishments. Data show that by the end of 2017, the inspection team had received more than 100,000 letters of complaint from the public. A total of 17,873 governmental officials and cadres were interviewed, 17,402 were held accountable, and 1,484 violators were detained. These investigations have resulted in unprecedented punishments with over 1.33 billion RMB (U.S. \$203 million) worth of fines being leveled on violated companies. The specific data of investigations and punishments for each batch are shown in Table 1.

Table 1 Investigations and punishments for each batch of inspections

\begin{tabular}{cccccc}
\hline Batches & $\begin{array}{c}\text { Public } \\
\text { complaints } \\
\text { (piece) }\end{array}$ & $\begin{array}{c}\text { Number of } \\
\text { interviews } \\
\text { (people) }\end{array}$ & $\begin{array}{c}\text { Number of } \\
\text { accountability } \\
\text { (people) }\end{array}$ & $\begin{array}{c}\text { Number of } \\
\text { detentions } \\
\text { (people) }\end{array}$ & $\begin{array}{c}\text { Amount of } \\
\text { fines } \\
\text { (billion RMB) }\end{array}$ \\
\hline Trial batch & 2856 & 65 & 366 & 123 & 0.03 \\
1st batch & 13316 & 2275 & 3492 & 327 & 0.22 \\
2nd batch & 15631 & 4666 & 3121 & 265 & 0.24 \\
3rd batch & 31457 & 6657 & 4660 & 405 & 0.37 \\
4th batch & 40706 & 4210 & 5763 & 364 & 0.47 \\
Total & $\mathbf{1 0 3 9 6 6}$ & $\mathbf{1 7 8 7 3}$ & $\mathbf{1 7 4 0 2}$ & $\mathbf{1 4 8 4}$ & $\mathbf{1 . 3 3}$ \\
\hline
\end{tabular}

Data source: Ministry of Ecology and Environment of the People's Republic of China (http://www.mee.gov.cn/)

\section{CEPI and pollution control}

164 With extraordinary resource mobilization and high concentrated political inputs, CEPI

165 is generally regarded as an effective measure to reduce pollution (Kostka and Zhang,

166 2018). This can be explained through the four procedures of CEPI.

167 The first procedure is stationing. During the stationing, the CEPI team conducted 168 an approximately unannounced month-long environmental protection inspection of 169 local party committees and governments, and related departments through listening to 170 reports, access to information, and field visits and reports from the public. In areas 171 with ineffective environmental protection, severe ecological damage, prominent 172 environmental problems, or deteriorated environmental quality, measures such as 
correspondence, interviews, accountability, restrictions on approvals, and notifications are taken and publicly exposed.

The second procedure is report feedback. The CEPI team will access the whole performance of the inspected cities and report a comprehensive inspection result to the central government. The report describes aspects needing rectification, such as lack of environmental regulations or inadequate pollution control. And after consideration, the local provincial governments will receive a list of CEPI feedback comments.

The third procedure is rectification and enforcement. Local provincial governments must issue a plan for collating the CEPI feedback within one month and making it public. The rectification plan should respond in detail to everything mentioned in the CEPI report. Meanwhile, the CEPI team will also check the rectification enforcement to prohibit superficial, selective, and emblematic rectification.

In addition, CEPI has moved from one-time enforcement to a routinized one that may have long-term effects on pollution reduction (Jia and Chen, 2019). The "Regulations on the Work of CEPI" issued in 2019 has clearly stated that CEPI will be carried out every five years, indicating a tendency of normalization and institutionalization. This particular tendency of CEPI may change local governments' behavior, public opinion, and enterprises' responses (Karplus and Wu, 2019). For instance, enterprises are more likely to take powerful measures to reduce pollution due to the threat of long-term sanctions, and local governments may focus more on pollution reduction.

\section{Data and method}

\section{Data}

\section{Water Pollution data}

As we stated above, we conduct the cost-benefit analysis based on investigating the impact of CEI on water pollution. Wastewater discharge has always been the main cause of water pollution ( $\mathrm{Hu}$ and Cheng, 2013). Water quality tends to deteriorate severely when the rivers flow through urban areas owing to the large amount of wastewater they receive (World Bank, 2006). So, following the previous literature of $\mathrm{Hu}$ et al. (2013) and Pan et al. (2020), we select the per capita amount of urban wastewater discharge (PUWD) to measure water pollution.

\section{CEPI data}

CEPI covers environmental problems in the water, air, and soil. As we focus on water pollution reduction, we choose cities having water pollution problems in CEPI reports 
209 in the first and second batches as our treatment group and the remaining cities as the 210 control group. Specifically, we manually downloaded the CEPI reports in all 211 provinces in the first and second batches and searched the cities with water pollution 212 problems. There are 57 and 47 cities with water pollution problems in the first and 213 second batches, respectively. In total, we select 500 cities as our study sample, of 214 which 104 are in the treatment group, and 396 are in the control group. The period of 215 our study is from 2009 to 2018.

216 The samples in the trail round-Hebei Province, are excluded from our analysis to 217 avoid potential bias since Hebei Province is a pilot province with more severe 218 pollution (Jia and Chen, 2019). We also eliminate the observations in the third and 219 fourth batches for two reasons. One is that these two batches started in 2017, which is 220 a really short time to analyze their effect on pollution reduction. Another is that the 221 central government also launched the CEPI "retrospective" in 2018, which will make 222 it harder to estimate the net effects of the third and fourth batches.

\section{Control variables}

224 The premise assumption of causal identification using the DID approach is that the 225 CEPI cities and the non-CEPI cities share common temporal trends in the absence of 226 CEPI implementation. However, since the selection of cities with water pollution 227 problems was non-random, which would pose a potential threat to the previous 228 assumption. Therefore, it is possible that the discrepancy in PUWD between the CEPI 229 and non-CEPI cities after the CEPI implementation could be owing to their 230 pre-existing differences.

231 To overcome this difficulty and enhance the accuracy of identification, we select 232 some control variables by referring to the method of Gentzkow (2006). Specifically, 233 we first find the key factors that influence the division of the CEPI and non-CEPI 234 cities and then control them. According to the "Central Ecological Environmental 235 Protection Inspections Work Regulations" issued by the central government, ${ }^{1}$ it is 236 specified that areas with major environmental problems and severe deterioration in 237 environmental quality would be the focus of CEPI. According to this criterion, we 238 selected the following four variables as our control variables.

239 (1) Industrial structure. This variable is measured by the ratio of the added value 240 of secondary industry to GDP. Cities with a higher percentage of secondary industry 241 added value over GDP are more likely to be selected as CEPI cities. In general, the 242 secondary industry is the main contributor to environmental pollution (Yang et al., 243 2019). The higher the ratio of secondary industry added value over GDP in a city, the 244 more serious the environmental pollution problem may be in that city.

245 (2) Population density. This variable is measured as the ratio between the number

\footnotetext{
${ }^{1} \mathrm{http}: / /$ www.gov.cn/xinwen/2019-06/17/content 5401085.htm
} 
of people in the urban area and the urban area's size. Cities with a greater population

247 density are more likely to select as CEPI cities because population density is a 248 primary contributor to environmental pollution (Dinda, 2004).

249 (3) Provincial capital-adjacent city. This is a dummy variable indicating whether 250 the city is the capital city of a province or its adjacent. Non-provincial capital-adjacent 251 cities may be more likely to be CEPI cities than provincial capital-adjacent cities. This 252 is because non-capital-adjacent cities are farther away from provincial governments 253 so that the local provincial governments may have weaker environmental regulation, 254 and thus non-capital-adjacent cities are also more likely to incur environmental 255 problems (Wang and Chen, 2020).

256 (4) City's administrative level. This is a dummy variable indicating whether a city 257 is a prefecture-level city. Prefecture-level cities are also more likely to become CEPI 258 cities than county-level cities. This is because prefecture-level cities have a larger 259 administrative area, a larger population, a higher degree of industrialization, and face 260 an increased political pressure (Sun et al., 2021). They may be more susceptible to 261 environmental problems and be subject to inspection ( $\mathrm{Li}$ and $\mathrm{Xu}, 2020$ ).

262 The data of the above variables are from China City Statistical Yearbook and 263 China City Construction Statistical Yearbook. Due to the missing values in some years 264 of some county-level cities, this paper supplements them by looking into the 265 Statistical Yearbook of various provinces and cities. Finally, we get the panel data of 266500 cities in China from 2009 to 2018. Table 2 shows the descriptive statistics of the 267 above variables.

268 Table 2 Descriptive statistical analysis of variables

\begin{tabular}{|c|c|c|c|c|}
\hline Variable & Definition & Mean & S.D. & $\mathrm{N}$ \\
\hline PUWD & $\begin{array}{l}\text { Per capita amount of urban wastewater discharge } \\
(\log )\end{array}$ & 3.502 & 0.817 & 4,993 \\
\hline Industrial structure & $\begin{array}{l}\text { The ratio of the added value of secondary industry } \\
\text { to GDP }\end{array}$ & 0.478 & 0.136 & 4,979 \\
\hline Population density & $\begin{array}{l}\text { The ratio of the total urban population to the urban } \\
\text { district area (people/square kilometer) }\end{array}$ & 609.329 & 722.953 & 4,994 \\
\hline $\begin{array}{l}\text { Provincial } \\
\text { capital-adjacent city }\end{array}$ & $\begin{array}{l}=1 \text { if a city is provincial capital-adjacent city; }=0 \\
\text { otherwise }\end{array}$ & 0.284 & 0.451 & 4,999 \\
\hline $\begin{array}{l}\text { City's administrative } \\
\text { level }\end{array}$ & $\begin{array}{l}=1 \text { if a city is prefecture-level city; }=0 \text { is } \\
\text { county-level city }\end{array}$ & 0.404 & 0.491 & 4,999 \\
\hline
\end{tabular}

\section{Empirical strategy}

270 To prevent some endogenous problems, such as omitted variables and measurement 271 errors from interfering with the study results, this paper regards CEPI as a 272 quasi-natural experiment and examines the impact of CEPI on water pollution using a 273 DID method.

274 First, we construct our baseline regression model with reference to the setting of 
Li et al. (2016) to estimate the average effect of CEPI on water pollution. Compared to the general DID model, this model is improved in two ways: (1) we use an interaction term between the policy dummy variable and time to control for the differences in time trends between CEPI cities and non-CEPI cities; (2) we assume that the effect of control variables on water pollution follows a unique time trend, and use an interaction term between the control variables and a time polynomial to control for the differences in the temporal evolution of water pollution correlated with CEPI. The baseline regression model takes the following form:

$$
\begin{aligned}
\text { PUWD }_{i t}=\alpha_{0} & +\alpha_{1} \text { CEPI }_{i t}+\gamma \text { Treatment }_{i} \times T+\left(C_{i t} \times f(T)\right)^{\prime} \theta+\mu_{i}+\lambda_{t} \\
& +\varepsilon_{i t}
\end{aligned}
$$

285 Where $P U W D_{i t}$ represents the per capita amount of urban wastewater discharge. $286 C E P I_{i t}$ is the CEPI variable that equals 1 in the years after city $i$ implemented CEPI 287 and 0 otherwise. Specifically, CEPI $I_{i t}=$ Treatment $_{i} *$ Post $_{t}$, where Treatment $_{i}$ 288 equals 1 if city $i$ belongs to CEPI cities and 0 otherwise; Post $t_{t}$ equals 1 if year $t$ 289 is after 2016 and 0 otherwise. Treatment $t_{i} \times T$ represents the linear time trend of 290 treatment, of which $T=y e a r-2008$. Control it $_{\text {it }}$ denotes a sequence of control 291 variables listed in Table 2, $f(T)=T+T^{2}+T^{3}$ is a 3 rd-degree polynomial of $\mathrm{T}$. $292 C_{i t} \times f(T)$ controls the time evolution trend of the control variables on water 293 pollution. In addition, this model is a two-way fixed effect model, in which $\mu_{i}$ and $294 \lambda_{t}$ represent the city fixed effect and the time fixed effect, respectively. $\varepsilon_{i t}$ is the 295 random perturbation term. $\alpha_{1}$ is the core estimation parameter of this paper, which 296 represents the net benefit of CEPI on water pollution control. If $\alpha_{1}<0$, it means that CEPI does contribute to water quality improvement, and the policy is effective.

298 Furthermore, this paper uses the event study method proposed by Jacobson et al. 299 (1993) to study the dynamic effects of CEPI on water pollution, which also can test 300 the common trend before the event shock. The specific estimation model is as 301 follows:

PUWD $_{i t}=\beta_{0}+\sum_{k \geq-6}^{2} \beta_{k}$ After $_{i t}^{k}+\gamma$ Treatment $_{i} \times T+\left(C_{i t} \times f(T)\right)^{\prime} \theta+\mu_{i}+\lambda_{t}+\varepsilon_{i t}$

303 Where the dummy variable After $_{i t}^{k}$ equals 1 if $t-2016=k$ and city $i$ belongs to the CEPI cities, 0 otherwise; $k=-6,-5,-4,-3,-2,-1,0,1,2$.

\section{The effects of CEPI on water pollution control}

\section{The average effects of CEPI on water pollution control}

307 Columns (1) and (2) in Table 3 show the average effect of CEPI on water pollution 308 control. In column (1), we only controlled the city and year fixed effects. The 309 estimated coefficient of the core explanatory variable CEPI is -0.197 and is significant 310 at the $1 \%$ significance level. It indicates a significant negative causal relationship 
311 between CEPI and wastewater discharge. That is, CEPI can significantly reduce 312 PUWD. As shown in column (2), the coefficient sign and significance level of the 313 core explanatory variable CEPI remain the same after we further included the 314 treatment time trend and the control variables. Specifically, CEPI can contribute to an $31511.2 \%$ reduction in PUWD for the CEPI cities than the non-CEPI cities. Therefore, we 316 draw a preliminary conclusion that CEPI significantly reduces water pollution.

317 Table 3 The average and dynamic effects of CEPI on water pollution control

\begin{tabular}{|c|c|c|c|}
\hline & \multicolumn{2}{|l|}{ Average effect } & \multirow{2}{*}{$\begin{array}{l}\text { Dynamic effect } \\
\text { (3) }\end{array}$} \\
\hline & (1) & (2) & \\
\hline$C E P I$ & $-0.197^{* * *}(0.041)$ & $-0.112^{* * *}(0.035)$ & \\
\hline Before6 & & & $0.018(0.035)$ \\
\hline Before 5 & & & $0.038(0.039)$ \\
\hline Before 4 & & & $0.027(0.041)$ \\
\hline Before3 & & & $-0.006(0.044)$ \\
\hline Before2 & & & $-0.042(0.053)$ \\
\hline Beforel & & & $-0.035(0.055)$ \\
\hline Current & & & $-0.120^{* *}(0.058)$ \\
\hline Afterl & & & $-0.206^{* * *}(0.065)$ \\
\hline After 2 & & & $-0.225^{* * *}(0.069)$ \\
\hline Treatment trend & & Yes & \\
\hline Control $\times T$ & & Yes & Yes \\
\hline Control $\times T^{2}$ & & Yes & Yes \\
\hline Control $\times T^{3}$ & & Yes & Yes \\
\hline City fixed effect & Yes & Yes & Yes \\
\hline Year fixed effect & Yes & Yes & Yes \\
\hline$R^{2}$ & 0.924 & 0.926 & 0.926 \\
\hline$N$ & 4993 & 4977 & 4977 \\
\hline
\end{tabular}

Notes: (1) Robust standard errors clustered at the city level are reported in parentheses; ${ }^{* * *},{ }^{* *}$, and ${ }^{*}$ indicate statistical significance at $1 \%, 5 \%$, and $10 \%$, respectively. (2) The Treatment trend in the third column is dropped because of the common line.

\section{The dynamic effects of CEPI on water pollution}

322 In section 4.1, we only analyze the average effects of CEPI on water pollution based 323 on a static viewpoint. But the performance of CEPI on water pollution control may 324 also last for a long time (Cheng et al., 2019). Hence, we continue to analyze the 325 dynamic effects of CEPI on water pollution in this part. The results are shown in 326 column (3) in Table 3.

327 We can see that CEPI is able to reduce PUWD consistently and significantly, and 328 the reduction effect is further enhanced over time. This finding is different from the 329 previous studies, which have generally assumed that CEI's policy effects would 330 rapidly fade or even disappear once the policy ends (Kostka and Zhang, 2018; van 331 Rooij et al., 2017; Zhao et al., 2020). The reason for the long-term positive effect of 332 CEPI on water pollution control is that CEPI has moved from one-time enforcement 333 to a routinized one (Jia and Chen, 2019). Because of this institutionalization of CEPI 
334 policy, governments, enterprises, and individuals face long-term pressure from

335 environmental inspections. As a result, local governments will adopt more stringent 336 environmental regulations to avoid environmental quality problems; enterprises will 337 improve their existing extensive production modes and consciously reduce emissions;

338 and the public will become more concerned about environmental issues (Jia and Chen, 339 2019).

\section{Threats to baseline results and robustness checks}

341 To ensure that our above findings are reliable, we performed additional robustness 342 checks to rule out the threats of some interference factors on the empirical results. 343 Specifically, the robustness checks include a common trend hypothesis test, an 344 expectation effect test, a placebo test, excluding the impact of other policies, and 345 adopting the propensity score matching and the difference-in-differences (PSM-DID) 346 method.

\section{Common trend hypothesis test}

348 The premise of using the DID approach to identify causal effects between CEPI and 349 PUWD is whether the CEPI and non-CEPI cities meet the common trend hypothesis. 350 We need to ensure that the PUWD in CEPI and non-CEPI cities are parallel before the 351 CEPI implementation. In that way, we can take the non-CEPI cities as the 352 counterfactual results of CEPI cities after the CEPI implementation and thus 353 accurately obtain the improved performance of CEPI on PUWD. Fig. 2 reports the 354 test results of the common trend hypothesis. We find that each year's estimated 355 coefficients before CEPI implementation are not significant at the $90 \%$ significance 356 level. This suggests that CEPI and non-CEPI cities have the same trend in PUWD 357 before 2016, satisfying the common trend hypothesis.

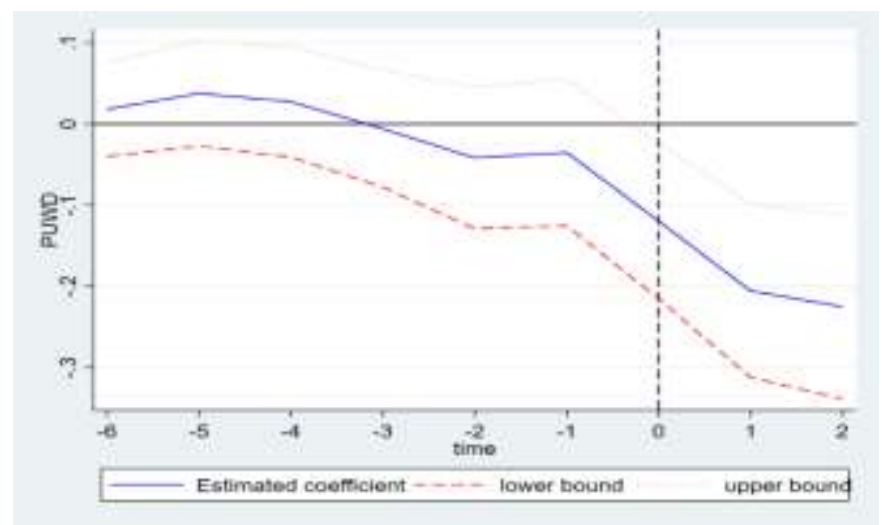

359 Fig. 2. Common trend hypothesis test

360 Note: The dashed red lines represent $90 \%$ confidence intervals.

$361 \quad$ Expectation effect test

362 CEPI was formally started in 2016, but as early as July 2015, the Chinese government 363 reviewed and approved the "Environmental Protection Inspection Program (Trial)", 
364 which clearly established the mechanism of CEPI. As a result, local governments may 365 have anticipated the implementation of CEPI and adjusted their environmental 366 management accordingly in advance. For this purpose, we draw on the method of Lu 367 et al. (2017) to test whether local governments have expectations for CEPI. The 368 specific approach is to add new interaction terms Treatment $\times$ post $_{2014}$ and 369 Treatment $\times$ post $_{2015}$ in model (1). The results are shown in Table 4 . We find that 370 the coefficients for Treatment $\times$ post $_{2014}$ and Treatment $\times$ post $_{2015}$ are not 371 significant, but the core explanatory variable CEPI is still significantly negative. 372 Thus, there is no significant expected effect until CEPI is officially launched.

373 Table 4 Expectation effect test

\begin{tabular}{llll}
\hline & $(1)$ & $(2)$ & $(3)$ \\
\hline CEPI & $-0.105^{* * *}(0.032)$ & $-0.105^{* * *}(0.031)$ & $-0.109^{* * *}(0.032)$ \\
Treatment $X_{\text {post }}$ 2014 & $-0.025(0.036)$ & & $-0.030(0.034)$ \\
Treatment Post $_{2015}$ & & $0.008(0.029)$ & $0.018(0.026)$ \\
$R^{2}$ & 0.970 & 0.973 & 0.971 \\
$N$ & 4817 & 4482 & 4977 \\
\hline
\end{tabular}

Notes: (1) Same as in Table 3, the regression controls for Treatment trend, Control $\times T$, Control $\times T^{2}$, Control $\times T^{3}$, Year fixed effect and City fixed effect. (2) Robust standard errors clustered at the city level are reported in parentheses; ${ }^{* * *},{ }^{* *}$, and ${ }^{*}$ indicate statistical significance at $1 \%, 5 \%$, and $10 \%$, respectively.

Placebo test

To exclude the influence of some unobservable factors on CEPI's water pollution control performance, we further performed two placebo tests on the benchmark model.

One placebo test is based on counterfactual time. We construct spurious CEPI implementation times through advancing CEPI implementation years by 1, 2, 3 years.

383 Suppose the coefficients of CEPI are not significant, suggesting that the reduction in 384 PUWD is indeed caused by CEPI. In that case, one can rule out the interference from 385 other factors before CEPI occurred. The regression results are shown in Table 5. We 386 find that none of the coefficients of CEPI are significant, which essentially allows us 387 to exclude the interference of other factors before the CEPI occurred. This goes some 388 way towards proving the robustness of the baseline regression result.

389 Table 5 Placebo test: Advancing the time of CEPI implementation

\begin{tabular}{llll}
\hline & One year in advance & Two years in advance & Three years in advance \\
\hline CEPI2015 & $-0.035(0.033)$ & & \\
CEPI2014 & & $-0.004(0.035)$ & \\
CEPI2013 & & & $0.016(0.031)$ \\
$R^{2}$ & 0.926 & 0.926 & 0.931 \\
$N$ & 4977 & 4977 & 4482 \\
\hline
\end{tabular}

Notes: The same as the notes in Table 4.

391 Another placebo test is based on the fictitious sample. Following Ferrara et al. 
(2012) and Fang et al. (2019), we randomly select 104 samples from a sample of 500

393 as spurious CEPI cities and the remaining samples as non-CEPI cities for regression.

394 To increase reliability, we repeat the above random selection steps 500 times. Fig. 3

395 reports the estimated coefficient probability density distribution. We can find that the

396 estimated coefficients are all centrally distributed at zero, while the baseline result $397(-0.112)$ is far from the center distribution. This result indicates that CEPI indeed 398 causes the reduction in PUWD and other random factors are unlikely to influence the 399 basic conclusion.

400

401

402

403

404

405

406

407

408

409

410

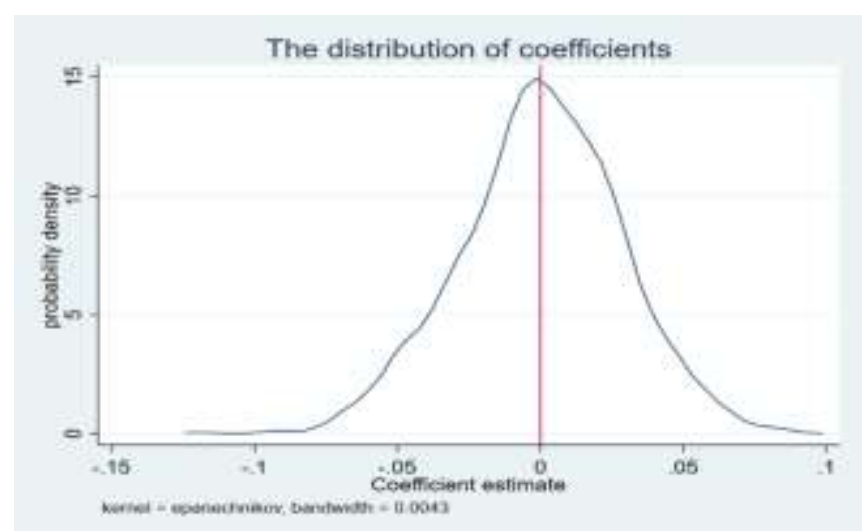

Fig. 3. Placebo test: fictitious sample

\section{Excluding the impact of other policies}

Considering that there may be other policies related to water pollution control in the period of CEPI implementation, the impact of CEPI on water pollution may be interfered. To address this issue, we need to exclude further the interference of these policies to perform robustness tests. Through the search, we found three policies, Environmental Protection Interview (EPI), Five-Year Plan (FYP), and CEPI "retrospective", which occurred during the same period of our study sample, would interfere with our result and need to be excluded.

First, the EPI, initiated by China's Ministry of Ecology and Environment in May 2014, aims to urge the government to deal with serious environmental problems and thus will have an impact on water pollution control. Until 2018, a total of 23 cities have implemented EPI for water pollution issues. Therefore, we excluded these 23 cities from the total sample to remove EPI's interference on the study result.

Second, the Chinese central government had mandated a binding pollutant reduction target for each province during 11th FYP, 12th FYP, and 13 FYP, and included these pollutant reduction targets in the performance appraisal of local officials as a means to reduce pollutant emissions (Kahn et al., 2015). These three FYPs may interfere with our result. To this end, we refer to the approach of Li et al. (2016) to exclude the interference of FYPs by controlling for the pollutant reduction targets in each province in the baseline regression model. 
Third, to check the rectification status of CEPI in each province, the Chinese government launched the CEPI "retrospective" in 2018 in some CEPI cities, which may threaten our baseline results. For this reason, this paper deletes the sample in 2018 and regresses only on the data from 2009 to2017. If the policy effect of CEPI is still significant after deleting the 2018 data, then it indicates that our baseline result is robust, that CEPI is indeed effective in controlling water pollution.

The results are shown in Table 6. We can find that the sign and significance of CEPI do not differ from the baseline regression result in all columns, indicating that our baseline result is not affected by other policies.

431 Table 6 Robustness test: Excluding other policies

\begin{tabular}{llll}
\hline & $\begin{array}{l}\text { Excluding the impact of } \\
\text { EPI }\end{array}$ & $\begin{array}{l}\text { Excluding the interference of } \\
\text { FYPs }\end{array}$ & $\begin{array}{l}\text { Excluding the threat of CEPI } \\
\text { "retrospective" }\end{array}$ \\
\hline$C E P I$ & $-0.109^{* * *}(0.035)$ & $-0.112^{* * *}(0.035)$ & $-0.107^{* * *}(0.034)$ \\
$R^{2}$ & 0.924 & 0.927 & 0.931 \\
$N$ & 4817 & 4977 & 4482 \\
\hline
\end{tabular}

Notes: The same as the notes in Table 4.

\section{PSM-DID method}

434 The CEPI and non-CEPI cities may have systematic differences before the CEPI 435 implementation, thus leading to a potential sample selectivity bias problem. The PSM 436 method can effectively solve sample selectivity bias, so we use the PSM-DID method 437 to test the robustness of the baseline regression result. Specifically, first, we use the 438 policy group dummy variable Treatment $_{i}$ to perform logit regression on the control 439 variable to obtain the propensity score value. Second, the methods of radius matching, 440 kernel matching, and nearest-neighbor matching were performed to match the 441 non-CEPI cities, respectively. Finally, we evaluate the policy performance of CEPI on 442 improving water pollution based on matched CEPI cities and non-CEPI cities. The 443 results in Table 7 show that the PSM-DID estimates are essentially identical to the 444 baseline regression result regardless of the matching method used, which further 445 arguing for the robustness of our baseline regression result, indicating that CEPI does 446 significantly reduce wastewater discharge.

447 Table 7 Robustness test: PSM-DID

\begin{tabular}{llll}
\hline & Radius matching & Kernel matching & Nearest-neighbor matching \\
\hline$C E P I$ & $-0.135^{* * *}(0.043)$ & $-0.113^{* * *}(0.035)$ & $-0.146^{* * *}(0.043)$ \\
$R^{2}$ & 0.937 & 0.926 & 0.936 \\
$N$ & 2233 & 4969 & 2236 \\
\hline
\end{tabular}


450 In this section, we conduct a calculation to estimate the benefits and costs of CEPI 451 based on the water pollution effects estimation results in Section 4. This preliminary 452 analysis provides an understanding of the range and magnitude of the benefits and 453 costs of using CEPI in tackling the pollution problem.

454 CEPI benefits: the health benefits from the reduction of mortality and morbidity

455 In the previous analysis, we have found that the CEPI decreased wastewater discharge 456 by $11.2 \%$. A large body of medical and epidemiological literature has confirmed that 457 the reduction in wastewater discharge is beneficial to human health (Landrigan et al., 458 2018; Schwarzenbach et al., 2010; Wang and Yang, 2016), such as decreasing infant 459 mortality (He and Perloff, 2016; Mettetal, 2019), lowing cancer morbidity and 460 mortality (Ebenstein, 2012; Zhang et al., 2014). Therefore, we measure the health 461 benefits of CEPI by estimating the reduction in mortality and morbidity caused by the 462 decline in wastewater discharge.

463 Firstly, we estimate the health benefits of CEPI on mortality, including infant 464 mortality and digestive cancer mortality. As for the health benefits of infant mortality 465 reduction, He and Perloff (2016) have estimated that a 33\% decrease in wastewater 466 discharge can result in a $0.6 \%$ increase in infant mortality. With this conclusion, we 467 can calculate that CEPI can reduce infant mortality by approximately $0.204 \%$ $468(0.6 \% \times 11.2 \% / 33 \%=0.204 \%)$. Further, based on China Health and Family Planning 469 Development Statistics Bulletin, the number of new births in China in 2015 was 16.55 470 million. We can calculate that CEPI can save the lives of $33,762(16,550,000 \times 0.204 \%$ $471=33,762)$ babies. And then, we calculate the health benefits by monetizing the 472 reduction in deaths using the Value of a Statistical Life (VSL), which is the amount 473 the government's willingness to pay to save a life. Based on the calculation of Li et al. 474 (2019), who have estimated that a VSL is about $\$ 2.3$ million, we ultimately calculate 475 that the health benefits of infant mortality reduction due to CEPI are $\$ 77.7$ billion $476\left(2,300,000 \times 33,762=77.7 \times 10^{9}\right)$. As for the health benefits of declining digestive 477 cancer mortality, Ebenstein (2012) has found that a $16.5 \%$ improvement in 478 wastewater discharge can decrease digestive cancer mortality by $9.7 \%$. Further, based 479 on the data that approximately 1 million people in China die of digestive cancer in $4802015,{ }^{2}$ we can estimate that CEPI can reduce the number of deaths from digestive 481 cancer in China by approximately 65,842 people $(1,000,000 \times 9.7 \% \times 11.2 \% / 16.5 \%=$ 48265,842 ), which could result in the health benefits of $\$ 151.4$ billion $483\left(2,300,000 \times 65,842=151.4 \times 10^{9}\right)$. Thus, the total benefits of CEPI on mortality are $484 \$ 229.1$ billion $\left(77.7 \times 10^{9}+151.4 \times 10^{9}=229.1 \times 10^{9}\right)$.

\footnotetext{
2 Cancer Report in China, 2019
} 
Secondly, we estimate the health benefits of CEPI on morbidity in China. Relevant studies have shown that the costs of morbidity in China are roughly 22-78\% of mortality costs (Landrigan et al., 2018). Therefore, we can conservatively calculate that the morbidity benefits attributable to CEPI are at least $\$ 50.4$ billion $\left(22 \% \times 229.1 \times 10^{9}=50.4 \times 10^{9}\right)$ based on the lower limit of $22 \%$.

Columns (1) and (2) in Table 9 present the health benefits of CEPI. In summary, the mortality and morbidity benefits resulting from CEPI amount to $\$ 279.5$ billion $\left(229.1 \times 10^{9}+50.4 \times 10^{9}=279.5 \times 10^{9}\right)$.

\section{CEPI Costs: the decrease in industrial value}

While improving the environment, CEPI inevitably brings certain costs, which are mainly derived from the decrease in industrial value (van der Kamp, 2017). According to relevant reports, enterprises' pollution problems have been the main content of public complaints, accounting for more than half of the total number of complaints. ${ }^{3}$ And, facing the pressure from inspection teams, the most common and direct approach of local governments is to close down many polluting enterprises and factories. For example, in Shandong Province, China, more than 100 companies with "poor" safety ratings for the transformation and upgrading of the chemical industry have been shut down. ${ }^{4}$ Therefore, this paper uses the decrease of China's secondary industry added value to estimate the costs caused by CEPI.

To accurately measure the costs of CEPI in China's secondary industry, we used the DID method to perform the evaluation. The specific form is as follows:

$$
S I V_{i t}=\rho_{0}+\rho_{1} C E P I_{i t}+\gamma \text { Treatment }_{i} \times T+\left(C_{i t} \times f(T)\right)^{\prime} \theta+\mu_{i}+\lambda_{t}+
$$
$\varepsilon_{i t}$

Where, $S I V_{i t}$ is the secondary industry real added value of city $i$ in year $t$. The data is obtained from China City Statistical Yearbook. To obey the normal distribution, the indicator $S I V_{i t}$ is logarithmized.

The result is shown in Table 8. We find that CEPI reduces the industrial value by $7.7 \%$. Based on the China Statistical Yearbook in 2015, the entire secondary industry added value is $\$ 2,496$ billion. ${ }^{5}$ Therefore, as shown in column 3 of Table 9, we can calculate the costs of CEPI in industrial value are $\$ 192.2$ billion $\left(2,496 \times 10^{9} \times 7.7 \%\right.$ $\left.=192.2 \times 10^{9}\right)$.

Table 8 The average effect of CEPI on the industrial value

\begin{tabular}{cc}
\hline & $S I V$ \\
\hline$C E P I$ & $-0.077^{* * *}(0.033)$ \\
$R^{2}$ & 0.974
\end{tabular}

\footnotetext{
${ }^{3}$ https://news.163.com/16/0803/07/BTHF2O4F00014AEE.html

${ }^{4} \mathrm{http}: / /$ www.chinatiredealer.com/news/show-37861.html

${ }^{5}$ Conversion based on RMB6.8 $=\$ 1$.
} 
Notes: The same as the notes in Table 4.

Table 9 Benefits and costs of CEPI

\begin{tabular}{ccccc}
\hline & \multicolumn{2}{c}{ Benefit (Billion \$) } & Cost (Billion \$) \\
& $(1)$ Infant & (2) Digestive cancer & $(3)$ \\
\hline $\begin{array}{c}\text { Benefit on } \\
\text { mortality }\end{array}$ & 77.7 & 17.1 & $\begin{array}{c}\text { The industrial value } \\
\text { reduction by CEPI } \\
\text { The real industrial }\end{array}$ & $7.7 \%$ \\
$\begin{array}{c}\text { Benefit on } \\
\text { morbidity }\end{array}$ & 151.4 & & value & 2496 \\
Total & & 33.3 & Total & 192.2
\end{tabular}

Notes: All the monetary terms are in 2015 U.S. dollars. The total health benefits come from the reduction of mortality and morbidity. The mortality benefit is based on the VSL of \$2.3 million (in 2015) as in Li et al. (2019), and the morbidity benefit is based on the lower limit of $22 \%$ of the mortality benefit in China as in (Landrigan et al., 2018). The total costs come from the decrease in industrial value. The total costs are based on the industrial value reduction by CEPI of 7.7\%, and the real industrual value is \$2496 billion in China in 2015 .

\section{Potential biases of cost-benefit analysis}

525 One should explain the benefits and costs estimates above with attention since there are two potential biases. One is the benefits of CEPI may be underestimated; the other is that the costs of CEPI may be overstated. To better understand these potential biases, in this section, we present detailed explanations.

On the one hand, there are three main reasons the calculation in Table 9 may underestimate the authentic benefits of CEPI. First, we only calculate the health benefits attributable to the improvement of water quality by CEPI. CEPI is a comprehensive environmental governance policy, and its effects are not only in water quality but also in air and soil, etc. Several studies have also empirically examined the performance of CEPI on air pollution control (Jia and Chen, 2019; Wang et al., 2021; $\mathrm{Xu}$ et al., 2020). But given that this paper focuses on the water pollution aspect, it does not include other aspects of environmental performance, such as air and soil, in our results. Therefore, an estimate restricted to water pollution would take only a modest fraction of the total benefits from CEPI. Second, in calculating the health benefits from improving water quality, we only calculate the mortality and morbidity

540 benefits in infants and digestive cancer. Previous studies have shown that water 541 pollution can cause not only digestive cancer but also other waterborne diseases, such

542 as acute diarrhea, legionnaires disease, and typhoid fever (Schwarzenbach et al., 543 2010). However, due to data problems, these correlative water quality benefits cannot 544 be obtained in our calculation and will make our measurement an understatement of 545 the total CEPI benefits. Third, the paper only calculates the direct health benefits 546 attributable to CEPI while neglecting the indirect benefits, such as improving the 547 government's enforcement ability and public environmental participation (Quan, 548 2020). These indirect benefits can also contribute to the total benefits of CEPI through 549 different forms. 
On the other hand, the calculations in Table 9 may overstate the authentic costs of CEPI. There are two reasons. First, most of the enterprises shut down in CEPI are highly polluted and outdated industries such as steel and chemical (van der Kamp, 2017). These highly polluted enterprises should be phased out even without CEPI

554 because they are harmful to the economy. If these highly polluted enterprises are not shut down, the economic losses will become even greater in the future. Therefore, the economic losses in Table 9 cannot fully be considered as costs due to CEPI from a long-term perspective. Second, CEPI can promote the green development of enterprises and accelerate their green transformation by eliminating outdated production capacity, and the short-term economic loss caused by CEPI can be transformed into long-term green production power (Tu et al., 2020). For example, an enterprise in Baoji, Shaanxi Province was ceased operations for rectification due to CEPI. However, after the renovation, the company eliminated many outdated production equipment and turned it into green production. ${ }^{6}$

In sum, a conservative estimation is that CEPI can generate at least $\$ 279.5$ billion in health benefits, outweighing the $\$ 192.2$ billion in costs. And after considering the potential biases, the gap between the benefits and costs will widen even more, and the cost-benefit ratio of CEPI will be further improved.

\section{Mechanisms: Why CEPI is cost-effective?}

\section{Theoretical analysis of the mechanism of CEPI}

The empirical analyses in the previous sections indicate that CEPI is effective in controlling water pollution, whether in the short term or in the long term, and thus the health benefits of CEPI are larger than the costs. However, there is an essential question as to the working mechanism of CEPI to reduce water pollution and thus become cost-effective. Based on previous literature, we propose there are three mechanisms, as shown in Fig. 4.

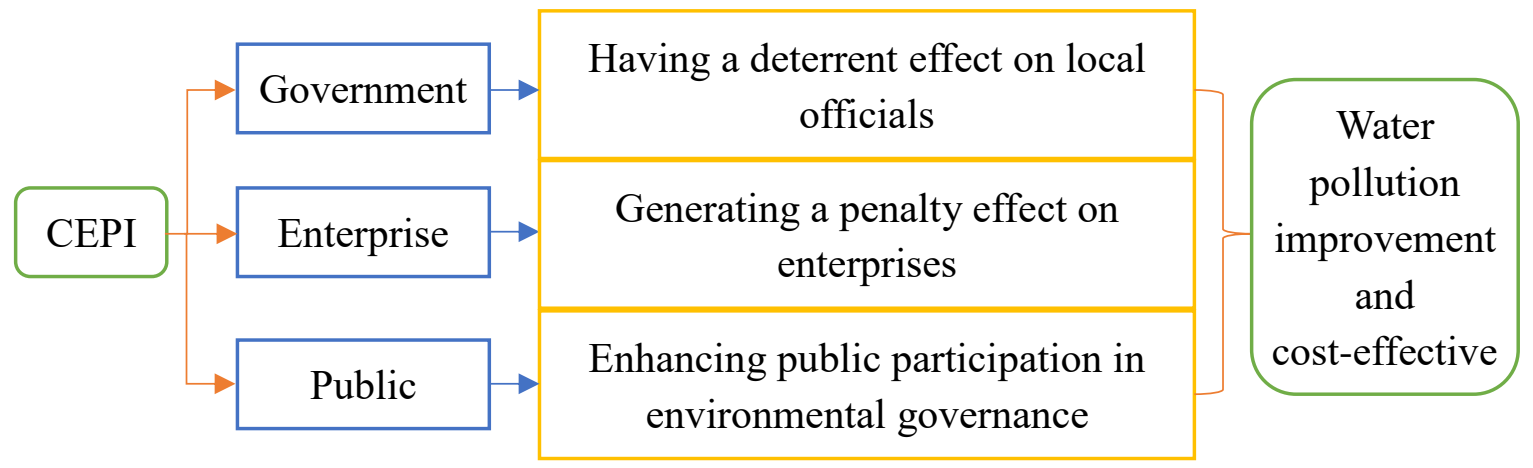

Fig. 4. The working mechanism of CEPI on water pollution improvement

First, CEPI has a deterrent effect on local officials and forces them to deal with

\footnotetext{
6 http://news.cnwest.com/lianbo/a/2018/11/09/17539371.html
} 
water pollution. In the past, the local governments tend to put economic growth in the first place (Chow, 2010). However, CEPI has changed this situation, prompting the local governments to make environmental protection as their immediate priority (Jia and Chen, 2019). Local party committees and governments have become the main inspection targets of CEPI. Government officials with unfavorable supervision and lax law enforcement will be interviewed and held accountable. As Table 1 in Section 2 shows, approximately 18,000 local officials were interviewed and held accountable during the inspection period, many of whom were senior-level local officials. This has brought a strong deterrent effect on other officials, thus greatly increasing local governments' enforcement efforts and forcing them to implement environmental protection policies seriously earnestly.

Second, CEPI has a penalty effect on enterprises. CEPI aims to reduce pollution through fining polluting enterprises, controlling their production, and forcing them to eliminate some outdated production equipment (van der Kamp, 2017). Through these measures, the enterprises are forced to comply with environmental laws and regulations, which in turn reducing environmental pollution. Meanwhile, the penalty on polluted enterprises enhances the reputation of the regulator and will have a magnified punishment effect on other firms (Shimshack and Ward, 2005).

Third, CEPI can enhance public participation in environmental governance. Public participation plays an important role in controlling environmental pollution (Wang and $\mathrm{Di}, 2002$ ). Lorentzen et al. (2014) and Xu et al. (2020) pointed out that public participation can create a bottom-up monitoring approach to discipline local governments, which significantly alleviates the severe information asymmetry that exists between central and local governments and pushes local governments to improve their environmental performance. During CEPI, public complaint channels are opened and the public are encouraged to provide environmental clues to the inspection team through phone calls, letters, and emails. The local governments are also required to provide timely feedback and disclose information on the public complaints they received. In addition, during the inspection period, the CEPI team will also select some letters to re-examine and verify local governments' response to the complaint letters, and officials who give inconsistent feedback will be directly held accountable. Through these measures, the governments can vigorously strengthen public participation in environmental protection, raise public awareness and enthusiasm for environmental protection (Jia and Chen, 2019).

\section{Empirical analysis of the mechanism}

In this section, we use the three-step approach proposed by Baron and Kenny (1986) to examine the above three mechanisms empirically. The specific models are as follows: 


$$
\begin{gathered}
\text { PUWD }_{i t}=\alpha_{0}+\alpha_{1} \text { CEPI }_{i t}+\gamma \text { Treatment }_{i} \times T+\left(C_{i t} \times f(T)\right)^{\prime} \theta+\mu_{i}+\lambda_{t} \\
+\varepsilon_{i t}
\end{gathered}
$$

$$
\begin{gathered}
M_{i t}=\tau_{0}+\tau_{1} C E P I_{i t}+\gamma \text { Treatment }_{i} \times T+\left(C_{i t} \times f(T)\right)^{\prime} \theta+\mu_{i}+\lambda_{t} \\
+\varepsilon_{i t} \\
\text { PUWD }_{i t}=\varphi_{0}+\varphi_{1} C E P I_{i t}+\varphi_{2} M_{i t}+\gamma \text { Treatment }_{i} \times T+\left(C_{i t} \times f(T)\right)^{\prime} \theta+\mu_{i}+\lambda_{t} \\
+\varepsilon_{i t}
\end{gathered}
$$

Where, $M_{i t}$ represents the three different mechanism variables mentioned in section 6.1. Following Deng (2019), we use the number of times local governments examining enterprises each year (Examine) to measure the deterrent effect of CEPI on local officials; the amount of fines (Fine) to measure the penalty effect of CEPI on enterprises; the number of public complaints (Complaint) to measure the degree of public participation. However, we can only obtain the above three mechanism indicators at the provincial level. Based on the method of Fan and Zhao (2019), we use the proportion of the city's industrial output to the provincial industrial output as the weight and multiply it by Examine, Fine, and Complaint to obtain the city-level data we need. Examine, Fine, and Complaint are treated as natural logarithms. $\alpha_{1}$ represents the total effect of CPEI on water pollution, $\varphi_{1}$ shows the direct effect of CPEI on water pollution, and $\tau_{1} \times \varphi_{2}$ is the indirect effect of CEPI on water pollution. If both $\tau_{1}$ and $\varphi_{2}$ are significant and the sign of $\tau_{1} \times \varphi_{2}$ is consistent with $\alpha_{1}$, it proves that the mediating effect is established.

The results are shown in Table 10. Column (1) reports the total effect of CEPI on water pollution. The result is consistent with the baseline results showing that CEPI has a significant negative impact on water pollution. Columns (2) and (3) demonstrate the analysis results of the deterrent effect. We can find that the coefficient of CEPI is significantly positive and the coefficient of Examine is significantly negative, indicating that CEPI can reduce water pollution by increasing the number of inspections launched by local governments. The same results are obtained in columns (4) and (5), columns (6) and (7). The results of columns (4) and (5) show that CEPI can reduce water pollution by increasing fines for polluting enterprises. The results of columns (6) and (7) prove that CEPI can reduce water pollution by increasing the number of public complaints. So, the three mechanisms of CEPI to reduce water pollution have been well demonstrated.

Table 10 The mechanism analysis of CEPI on water pollution

\begin{tabular}{cccccccc}
\hline & & \multicolumn{2}{c}{ Deterrent effect } & \multicolumn{2}{c}{ Penalty effect } & \multicolumn{2}{c}{ Public participation effect } \\
\cline { 3 - 7 } & $(1)$ & $(2)$ & $(3)$ & $(4)$ & $(5)$ & $(6)$ & $(7)$ \\
& $P U W D$ & Examine & $P U W D$ & Fine & PUWD & Complaint & $P U W D$ \\
\hline \multirow{2}{*}{ CEPI } & $-0.112^{* * * *}$ & $0.263^{* * *}$ & $-0.094^{* * *}$ & $0.296^{* * *}$ & $-0.097^{* * *}$ & $0.709^{* * *}$ & $-0.088^{* *}$ \\
& $(0.035)$ & $(0.101)$ & $(0.035)$ & $(0.095)$ & $(0.036)$ & $(0.101)$ & $(0.035)$ \\
\multirow{2}{*}{ Examine } & & & $-0.036^{* * *}$ & & & & \\
& & & $(0.009)$ & & & &
\end{tabular}


Complaint

\begin{tabular}{ccc} 
& & $-0.022^{* * * *}$ \\
& & $(0.008)$ \\
0.939 & 0.842 & 0.939 \\
4725 & 4726 & 4725 \\
\hline
\end{tabular}

\section{Conclusion}

659 As an important means of environmental governance, CEI is always criticized for its 660 high cost. The CEPI provides a good opportunity for us to study the benefits and costs 661 of CEI. Based on annual panel data from 500 cities during 2009-2018, we regard the 662 CEPI as a quasi-natural experiment and use the DID method to perform a rough 663 calculation to compare the benefits and costs of CEPI based on the water pollution 664 effects estimates of CEPI on water pollution. Our empirical results show that: first, 665 CEPI has led to an average $11.2 \%$ reduction in water pollution, and this effect remained significant in the long term. A series of robustness checks demonstrate that this baseline result is reliable. Second, the benefits and costs estimation results indicate that the total health benefits from the reduction in mortality and morbidity attributable to CEPI amount to $\$ 279.5$ billion, which outweigh the $\$ 192.2$ billion costs caused by CEPI. The gap widens further after considering the potential biases. Third, the analysis of the mechanisms shows that CEPI reduces water pollution and becomes cost-effective mainly through deterring local officials, punishing polluting enterprises, and increasing public participation.

Based on the above findings, the policy implications of this paper are as follows.

First, the government should continue to promote the normalization of the CEPI system vigorously. From the cost-benefit analysis results, although CEPI has caused certain costs, it can also bring greater benefits to society. CEPI can not only reduce the pollutant emissions of enterprises and eliminate outdated production capacity but also restrain local officials from inaction and harboring polluting enterprises, thus improving environmental quality and promoting green economic development. Therefore, in the following inspection, the central government can work in various ways, such as organizing periodic spot checks, conducting special inspections and CEPI "retrospective", and crackdown on undesirable phenomena such as "superficial rectification", "perfunctory rectification", and "one-size-fits-all", to make environmental governance have long-term performance.

Second, the government should strengthen citizens' awareness of environmental protection, open multi-channel reporting platforms, and improve bottom-up environmental monitoring systems. Water pollution is closely related to citizens' lives, and their environmental awareness, attitudes, and perceptions of environmental risks 
690 will directly or indirectly influence local governments' environmental governance 691 (Wang and Watanabe, 2019). The government should transmit the harms caused by 692 environmental problems to the public through various mediums, such as TV, internet, 693 media, and newspapers, to raise citizens' environmental awareness. The government 694 should also liberalize multiple reporting channels and conduct strict verification, 695 quick processing, and timely feedback on environmental problems reported by 696 citizens, thus forming a bottom-up inspection mechanism to discipline the 697 environmental behavior of local governments.

698 Third, the government should adopt high-tech means and innovating inspection 699 methods. The asymmetry of pollution information is a major obstacle in 700 environmental governance. The government can establish the central ecological and 701 environmental protection inspection information system, and increase the application 702 of technologies, such as satellite remote sensing, infrared identification, drones, and 703 big data, to find environmental problems and improve environmental governance. 
704 Author contribution Dan Pan: Conceptualization, Funding acquisition, Project 705 administration, and Writing - review and editing; Wei Hong: Methodology, Data curation, 706 Formal analysis, Software, and Writing — original draft.

707 Funding This study was supported by the National Youth Talent Support Program, and the 708 National Natural Science Foundation of China (No. 71863016; No. 71673123).

709 Data availability The data used to support the findings of this study are available from the 710 corresponding author upon request.

\section{Declarations}

712 Ethics approval and consent to participate Not applicable.

713 Consent for publication All authors have given their consent to publish this research 714 article.

715 Conflict of interest The authors declare that they have no known competing financial 716 interests or personal relationships that could have appeared to influence the work reported 717 in this paper.

\section{References}

Bank, W. (2006) Water quality management: policy and institutional considerations.

Baron, R. M., Kenny, D. A. (1986) The moderator-mediator variable distinction in social psychological research: conceptual, strategic, and statistical considerations. J Pers Soc Psychol 51(6): 1173-1182. https://doi.org/10.1037/0022-3514.51.6.1173

Cheng, J., Yi, J., Dai, S., Xiong, Y. (2019) Can low-carbon city construction facilitate green growth? evidence from China's pilot low-carbon city initiative. J Clean Prod 231: 1158-1170. https://doi.org/10.1016/j.jclepro.2019.05.327

Chow, G. C. (2010) China's environmental policy: a critical survey. Princeton University Center for Economic Policy Studies No. 206. https://doi.org/10.1142/9789814368810_0027

Deng H. (2019) Does central environmental protection supervision improved air quality in China? Central China Normal University (in Chinese).

Dinda, S. (2004) Environmental Kuznets Curve hypothesis: a survey. Ecol Econ 49(4): 431-455. https://doi.org/10.1016/j.ecolecon.2004.02.011

Ding, Z., Gao, X., Qian, X., Wang, H. (2021) Governmental inspection and local legislation on environmental protection: evidence from China. J Econ Surv. https://doi.org/10.1111/joes.12431

Duflo, E., Greenstone, M., Pande, R., Ryan, N. (2018) The value of regulatory discretion: estimates from environmental inspections in India. Econometrica 86(6): 2123-2160. https://doi.org/10.3982/ECTA12876

Ebenstein, A. (2012) The consequences of industrialization: evidence from water pollution and digestive cancers in China. Rev Econ Stat 94(1): 186-201. https://doi.org/10.1162/REST_a_00150

Fan, Z., Zhao, R. (2019) Does rule of law promote pollution control? evidence from the establishment of the environmental court. Econ. Res. J. 54(3): 21-37 (in Chinese).

742 Fang, J., Liu, C., Gao, C. (2019) The impact of environmental regulation on firm exports: evidence 
from environmental information disclosure policy in China. Environ. Sci. Pollut. Res. 26: 37101-37113. https://doi.org/10.1007/s11356-019-06807-2

Ferrara, E. L., Chong, A., Duryea, S. (2012) Soap operas and fertility: evidence from Brazil. Am Econ J Appl Econ 4(4): 1-31. https://doi.org/10.1257/app.4.4.1

Gentzkow, M. (2006) Television and voter turnout. Q J Econ 121(3): 931-972. https://doi.org/10.1162/qjec.121.3.931

Gray, W. (2015) Environmental regulations and business decisions. IZA World of Labor. https://doi.org/10.15185/izawol.187

Greenstone, M., He, G., Li, S., Zou, E. (2020) China's war on pollution: evidence from the First Five Years. NBER Working Paper NO. w28467. https://www.nber.org/papers/w28467

He, G., Perloff, J. M. (2016) Surface water quality and infant mortality in China. Econ Dev Cult Change 65(1): 119-139. https://doi.org/10.1086/687603

He, L., Geng, M. (2020) Can Chinese central government inspection on environmental protection Improve air quality? Atmosphere 11(10): 1025. https://doi.org/10.3390/atmos11101025

Hu, X., Wu, H., Ge, D., Zhu, D. W., Zhou, W. B., Cheng, D. S. (2013) Method for efficiency assessment of wastewater treatment and application based on DEA. Water Resour. Prot 4: 77-81. (in Chinese). https://doi.org/10.19343/j.cnki.11-1302/c.2020.04.005

$\mathrm{Hu}$, Y., Cheng, H., 2013. Water pollution during China's industrial transition. Environ Dev 8: 57-73. https://doi.org/10.1016/j.envdev.2013.06.001

Jacobson, L. S., LaLonde, R. J., Sullivan, D. G. (1993) Earnings losses of displaced workers. Am Econ Rev 83(4): 685-709. https://www.jstor.org/stable/2117574

Jia, K., Chen, S. (2019) Could campaign-style enforcement improve environmental performance? evidence from China's central environmental protection inspection. J Environ Manage 245: 282-290. https://doi.org/10.1016/j.jenvman.2019.05.114

Kahn, M. E., Li, P., Zhao, D. (2015) Water Pollution Progress at Borders: the Role of Changes in China's Political Promotion Incentives. Am Econ J Econ Policy 7(4): 223-242. https://doi.org/10.1257/pol.20130367

Karplus, V. J., Wu, M. (2019) Crackdowns in Hierarchies: evidence from China's Environmental Inspections. MIT CEEPR Working Paper No. 5700-19. https://dx.doi.org/10.2139/ssrn.3449177

Kostka, G., Zhang, C. (2018) Tightening the grip: environmental governance under Xi Jinping. Environ Polit 27: 769-781. https://doi.org/10.1080/09644016.2018.1491116

Landrigan, P. J., Fuller, R., Acosta, N. J. R., et al. (2018) The lancet commission on pollution and health. The Lancet 391: 462-512. https://doi.org/10.1016/S0140-6736(17)32345-0

Li, P., Lu, Y., Wang, J. (2016) Does flattening government improve economic performance? evidence from China. J Dev Econ 123: 18-37. https://doi.org/10.1016/j.jdeveco.2016.07.002

Li, R., Zhou, Y., Bi, J., Liu, M., Li, S. (2020) Does the central environmental inspection actually work? J Environ Manage 253: 109602. https://doi.org/10.1016/j.jenvman.2019.109602

Li, S., Liu, Y., Purevjav, A., Yang, L. (2019) Does subway expansion improve air quality? J Environ Econ Manag 96: 213-235. https://doi.org/10.1016/j.jeem.2019.05.005

Li, S., Xu, B. (2020) Environmental regulation and technological innovation-evidence from the prefectural level in China. Modern Econ. Res. (11): 31-40 (in Chinese). https://doi.org/10.13891/j.cnki.mer.2020.11.006 
Li, X., Yang, X., Wei, Q., Zhang, B. (2019) Authoritarian environmentalism and environmental policy implementation in China. Resour Conserv Recycl 145: 86-93. https://doi.org/10.1016/j.resconrec.2019.02.011

Liu, G., Yang, Z., Chen, B., Zhang, Y., Su, M., Ulgiati, S. (2016) Prevention and control policy analysis for energy-related regional pollution management in China. Appl Energ 166: 292-300. https://doi.org/10.1016/j.apenergy.2015.06.032

Liu, N. N., Lo, C. W., Zhan, X., Wang, W. (2015) Campaign-style enforcement and regulatory compliance. Public Admin Rev 75(1): 85-95. https://doi.org/10.1111/puar.12285

Lorentzen, P., Landry, P., Yasuda, J. (2014) Undermining authoritarian innovation: the power of China's industrial giants. J Polit Econ 76: 182-194. https://doi.org/10.1017/S0022381613001114

Lu, Y., Tao, Z., Zhu, L. (2017) Identifying FDI spillovers. J Int Econ 107: 75-90. https://doi.org/10.1016/j.jinteco.2017.01.006

Mettetal, E. (2019) Irrigation dams, water and infant mortality: evidence from South Africa. J Dev Econ 138: 17-40. https://doi.org/10.1016/j.jdeveco.2018.11.002

Pan, D., Hong, W., Kong, F. (2020) Efficiency evaluation of urban wastewater treatment: evidence from 113 cities in the Yangtze River Economic Belt of China. J Environ Manage 270: 110940. https://doi.org/10.1016/j.jenvman.2020.110940

Quan, Y. (2020) Public participation in campaign-style enforcement: Evidence from central environmental inspection.

805

Ran, R. (2013) Perverse incentive structure and policy implementation gap in China's local environmental politics. J Environ Pol Plan 15(1): https://doi.org/10.1080/1523908X.2012.752186

Schwarzenbach, R. P., Egli, T., Hofstetter, T. B., von Gunten, U., Wehrli, B. (2010) Global water pollution and human health. Annu Rev Env Resour 35: 109-136. https://doi.org/10.1146/annurev-environ-100809-125342

Shimshack, J. P., Ward, M. B. (2005) Regulator reputation, enforcement, and environmental compliance. J Environ Econ Manag 50(3): 519-540. https://doi.org/10.1016/j.jeem.2005.02.002

Shimshack, J. (2014) The economics of environmental monitoring and enforcement. Annu Rev Resour Econ 6(1): 339-360. https://doi.org/10.1146/annurev-resource-091912-151821

Sun, X., Wang, W., Pang, J., Liu, X., Zhang, M. (2021) Study on the evolutionary game of central government and local governments under central environmental supervision system. J Clean Prod 296: 126574. https://doi.org/10.1016/j.jclepro.2021.126574

Tao, T., Xin, K. (2014) Public health: A sustainable plan for China's drinking water. Nature 511: 527-528. https://doi.org/10.1038/511527a

Tian, M., Xu, G., Zhang, L. (2019) Does environmental inspection led by central government undermine Chinese heavy-polluting firms' stock value? the buffer role of political connection. J Clean Prod 236: 117695. https://doi.org/10.1016/j.jclepro.2019.117695

Tu, Z., Deng, H., Shen, R., Gan, T. (2020) The environmental and economic benefits of the Central Environmental Protection Supervision: evidence from policy pilot in Hebei. Econ. Rev. (1): 3-16 (in Chinese). https://doi.org/10.19361./j.er.2020.01.01

van der Kamp, D. S. (2017) Clean air at what cost the rise of blunt force pollution regulation in China. eScholarship, 
van Rooij, B., Zhu, Q., Qiliang, W. (2017) Centralizing Trends and Pollution Law Enforcement in China. China Q 231: 583-606. https://doi.org/10.1017/S0305741017000935

Wang, H., Di, W. (2002) The determinants of government environmental performance: an empirical analysis of chinese townships. World Bank Policy Research Working Paper. http://library1.nida.ac.th/worldbankf/fulltext/wps02937.pdf

Wang, L., Watanabe, T. (2019) Effects of environmental policy on public risk perceptions of haze in Tianjin city: a difference-in-differences analysis. Renew. Sust. Energ. Rev. 109: 199-212. https://doi.org/10.1016/j.rser.2019.04.017

Wang, Q., Yang, Z. (2016) Industrial water pollution, water environment treatment, and health risks in China. Environ Pollut 218, 358-365. https://doi.org/10.1016/j.envpol.2016.07.011

Wang, W., Sun, X., Zhang, M. (2021) Does the central environmental inspection effectively improve 112274. https://doi.org/10.1016/j.jenvman.2021.112274

Wang, Y., Chen, X. (2020) River chief system as a collaborative water governance approach in China. Int J Water Resour Dev 36: 610-630. https://doi.org/10.1080/07900627.2019.1680351

Wang, Y., Zhao, Y. (2021) Is collaborative governance effective for air pollution prevention? a case study on the Yangtze river delta region of China. J Environ Manage 292, 112709. https://doi.org/10.1016/j.jenvman.2021.112709

Wu, R., Hu, P. (2019) Does the "Miracle Drug” of environmental governance really improve air quality? evidence from China's system of central environmental protection inspections. Int J Env Res Pub He 16(5): 850. https://doi.org/10.3390/ijerph16050850

Xiang, C., van Gevelt, T. (2020) Central inspection teams and the enforcement of environmental regulations in China. Environ Sci Policy 112: 431-439. https://doi.org/10.1016/j.envsci.2020.06.018

Xu, F., Tian, M., Yang, J., Xu, G. (2020) Does environmental inspection led by the central government improve the air quality in China? the moderating role of public engagement. Sustainability 12(8): 3316. https://doi.org/10.3390/su12083316

Yang, X., Lin, S., Li, Y., He, M. (2019) Can high-speed rail reduce environmental pollution? evidence from China. J Clean Prod 239: 118135. https://doi.org/10.1016/j.jclepro.2019.118135

Yu, X., Wang, H. (2013) How should the center lead China's reforestation efforts?-policy making games between central and local governments. Resour Conserv Recycl 80: 64-84. https://doi.org/10.1016/j.resconrec.2013.09.001

Zeng, H., Dong, B., Zhou, Q., Jin, Y. (2021) The capital market reaction to central environmental protection inspection: evidence from China. J Clean Prod 279: 123486. https://doi.org/10.1016/j.jclepro.2020.123486

Zhang, X., Zhuang, D., Ma, X., Jiang, D. (2014) Esophageal cancer spatial and correlation analyses: water pollution, mortality rates, and safe buffer distances in China. J Geogr Sci 24: 46-58. https://doi.org/10.1007/s11442-014-1072-8

Zhao, Y., Zhang, X., Wang, Y. (2020.) Evaluating the effects of campaign-style environmental governance: evidence from environmental protection interview in China. Environ Sci Pollut R 27: 28333-28347. https://doi.org/10.1007/s11356-020-09243-9 